\title{
25-Hydroxy Vitamin D Exhibits NGF-like Activity in PC12 Cells Miyako Mochizuki ${ }^{1}$ and Noboru Hasegawa ${ }^{2^{*}}$ \\ ${ }^{1}$ Kyoto Bunkyo Junior College, 80 Senzoku, Makishima-cho, Uji, Kyoto 611-0041, Japan \\ ${ }^{2}$ Doshisha Women's College of Liberal Arts, Kodo, Kyotanabe, Kyoto 610-0395, Japan
}

\begin{abstract}
Background: In our previous study, 25-hydroxy vitamin D (25OHD) supplementation was associated with improved serum vitamin D levels and, possibly, improved cognitive function. In response to nerve growth factor, PC12 cells first undergo proliferation, followed by growth arrest and differentiation. We studied the effects of $25 \mathrm{OHD}$ on neurite elongation in PC12 cells.
\end{abstract}

Methods: PC12 cells were treated with 10ng/mL NGF with or without $6 \mathrm{nmol} / \mathrm{L}$ of 25OHD for 9 days. Phase-contrast micrographs were recorded and cells with a neurite outgrowth longer than the diameter of their cell body were counted. To investigate the expression level of Akt protein, PC12 cells were preincubated with $10 \mathrm{ng} / \mathrm{mL}$ NGF with or without $6 \mathrm{nmol} / \mathrm{L}$ of $25 \mathrm{OHD}$ for 4 days, and lysates were assayed using a commercially available AKT/AKT ELISA kit.

Results: In the presence of NGF, 25OHD induced an increase in both the number of cells with extended neurites and the length of neurites. Expression of phosphorylated Akt was enhanced by 25OHD without NGF and 25OHD up-regulated NGF-induced phosphorylation.

Conclusion: These findings show that 25OHD displays NGF-mimicking and NGF-enhancing neurogenic activity in PC12 cells, which potentially depended on activating P3K/AKT signaling pathways.

\section{Introduction}

Vitamin D is a liposoluble pleiotropic hormone that is mainly synthesized in the skin from cholesterol precursors upon exposure to solar 280-315nm (UVB) radiation, or acquired from dietary sources such as oily fish [1].

Vitamin D is a secosteroid associated with peripheral calcium homeostasis and nervous system function [2]. Vitamin D is available in two forms, vitamin D2 from plants and D3 from animals. Both vitamin D2 and D3 are biologically inert and require activation through two hydroxylation processes involving 25-hydrooxylase (CYP2R1) and 1a-hydroxylase (CYP27B1), located in the liver and kidney, respectively [3]. 1, 25-dihydroxyvitamin D is a biologically active metabolite produced by two hydroxylation reaction steps in the nervous system [4].

However, low 25-hydroxy vitamin D (25OHD) levels were recently associated with greater risk of cognitive impairment in older as well as younger adults using the Montreal Cognitive Assessment (MoCA) Arabic version [5].In a previous study, we showed that 25OHD supplementation was associated with improved serum vitamin D levels and possibly improved cognitive function [6].

Rat pheochromocytoma-derived cell line PC12 cells undergo proliferation followed by growth arrest and differentiation in response to nerve growth factor [7]. One aim of the present study was to show that 25OHD act directly on neuronal cells.

Akt is activated by a variety of mitogen factors and cytokines as well as NGF [8]. Serine / threonine kinase (Akt) is involved in the neuronal differentiating effect of nerve growth factor (NGF) [9]. Another aim of the present study was to show that the phosphatidylinositol 3-kinase/ AKT (PI3K/AKT) signaling pathway is involved in the 25OHD induced neurogenic activity.

Therefore, the present study was designed to investigate the effect of 25OHDonNGF induced neurite elongation and phosphorylated AKT (Ser473)/ total AKT in PC12 cells.

\section{Materials and Methods}

\section{Products}

NGF $\beta$ from rats was purchased from (Sigma, USA). 25OHD was purchased from Immundiagnostik AG (Bensheim, Germany).

\section{Cell culture and differentiation}

The rat adrenal pheochromocytoma-derived cell line PC12 was obtained from RIKEN Bio Resource Research Center (Ibaraki, Japan) and maintained in Dulbecco's modified Eagle's medium (Thermo Fishier Scientific, Japan), supplemented with $10 \%$ deactivated horse serum, $10 \%$ deactivated bovine serum, $100 \mathrm{unit} / \mathrm{mL}$ penicillin and $100 \mu \mathrm{g} / \mathrm{mL}$ streptomycin sulfate, at $5 \% \mathrm{CO}_{2}, 37^{\circ} \mathrm{C}$. PC12 cells were seeded at a density of $1.5 \times 10^{5}$ cells. After $24 \mathrm{~h}$ of incubation, the PC12 cells were treated with $10 \mathrm{ng} / \mathrm{mL}$ NGF with or without $6 \mathrm{nmol} / \mathrm{L}$ of 25OHD for 9 days.

\section{Measurement of neurite elongation}

Phase-contrast micrographs were recorded on a personal computer using a charge coupled device camera (Ikegami, Japan), followed by analysis using software (Miotic Images Plus 2.1S; Shimadzu, Japan). Cells with protrusions longer than the cell body diameter were counted as cell with neurites. PC12 cells were treated with NGF for 9 days for the proper tracing of neurites belonging to a specific cell body.

"Corresponding Author: Prof. Noboru Hasegawa, Doshisha Women's College of Liberal Arts, Kodo, Kyotanabe, Kyoto 610-0395, Japan, Tel: +81-774-65-8855, Fax: +81-774-65-8820; E-mail: nhasegaw@dwc.doshisha.ac.jp

Citation: Mochizuki M, Hasegawa N (2021) 25-Hydroxy Vitamin D Exhibits NGF-like Activity in PC12 Cells. Int J Clin Nutr Diet 7: 159. doi: https://doi. org/10.15344/2456-8171/2021/159

Copyright: (C) 2021 Mochizuki et al. This is an open-access article distributed under the terms of the Creative Commons Attribution License, which permits unrestricted use, distribution, and reproduction in any medium, provided the original author and source are credited. 
Citation: Mochizuki M, Hasegawa N (2021) 25-Hydroxy Vitamin D Exhibits NGF-like Activity in PC12 Cells. Int J Clin Nutr Diet 7: 159. doi: https:/doi. org/10.15344/2456-8171/2021/159

Page 2 of 4

\section{Phosphorylated AKT / total AKT (pAKT/AKT) assay}

Cells were treated with $10 \mathrm{ng} / \mathrm{mL}$ NGF with or without $6 \mathrm{nmol} / \mathrm{L}$ of $25 \mathrm{OHD}$ for 4 days and washed 3 times with ice-cold phosphatebuffered saline and lysed with radioimmunoprecipitation buffer (RIPA) and protease inhibitor (Santa Cruz Biotechnology, USA). Lysates were centrifuged for $10 \mathrm{~min}$ at $12,000 \mathrm{~g}$ and supernatants were analyzed for protein concentration using Pierce ${ }^{\mathrm{Tw}} \mathrm{BCA}$ Protein Assay kit (Peirce, Rockford, IL). pAKT/AKT were assayed using the commercially available ELISA kit (AKT1/2/3(pS473)+AKT1 Total SimpleStep ELISA ${ }^{\mathrm{TM}}$ Kit, Abcam, UK).

\section{Statistical analyses}

The data are expressed as mean \pm SE, and the mean values of each group were compared in a one-way analysis of variance. A p-value of $<0.05$ was considered to be statistically significant. Analyses were carried out using SPSS 21 for Windows (IBM, Japan).

\section{Results}

\section{Effect of 25OHD on NGF-induced neurite formation of PC12 cells}

PC12 cells are known to differentiate into sympathetic nerve-like cells and show neurite outgrowth in the presence of NGF [7]. The morphological changes in PC12 cells after treatment with $6 \mathrm{nmol}$ of $25 \mathrm{OHD}$ and $10 \mathrm{ng} / \mathrm{mL}$ NGF are displayed in Figure 1A.
25OHD induced an increase in the length of neurites in the presence of NGF (Figure 1B). These results indicate that 25OHD exhibited NGF-enhancing activity in PC12 cells.

\section{Effect of 25OHD on phosphorylation level of Akt}

Akt is involved in the neuronal differentiating effect of NGF [10]. Akt is activated by a variety of mitogen factors and cytokines as well as NGF [8]. In this study, NGF enhanced phosphorylation of Akt (Figure 2). Expression of phosphorylated Akt was enhanced by $25 \mathrm{OHD}$ without NGF and 25OHD up-regulated NGF-induced phosphorylation (Figure 2).

PC12 cells were cultured with NGF for 4 days with and without 6 $\mathrm{nmol} / \mathrm{L}$ of 25OHD. Lysate was subjected to the pAkt/Akt assay. Each experiment was repeated three times. Data are expressed as pAKT/ AKT (\%) and mean \pm SE.

\section{Discussion}

Many studies have shown that NGF enhances neurite outgrowth and Akt phosphorylation $[7,8,10]$. In our study, 25OHD was also shown to enhance NGF-induced acetylcholinesterase activity [11].

In this study, 25OHD enhanced NGF-induced neurite growth of PC12 cells and up-regulated NGF-induced Akt phosphorylation.

\section{(A)}
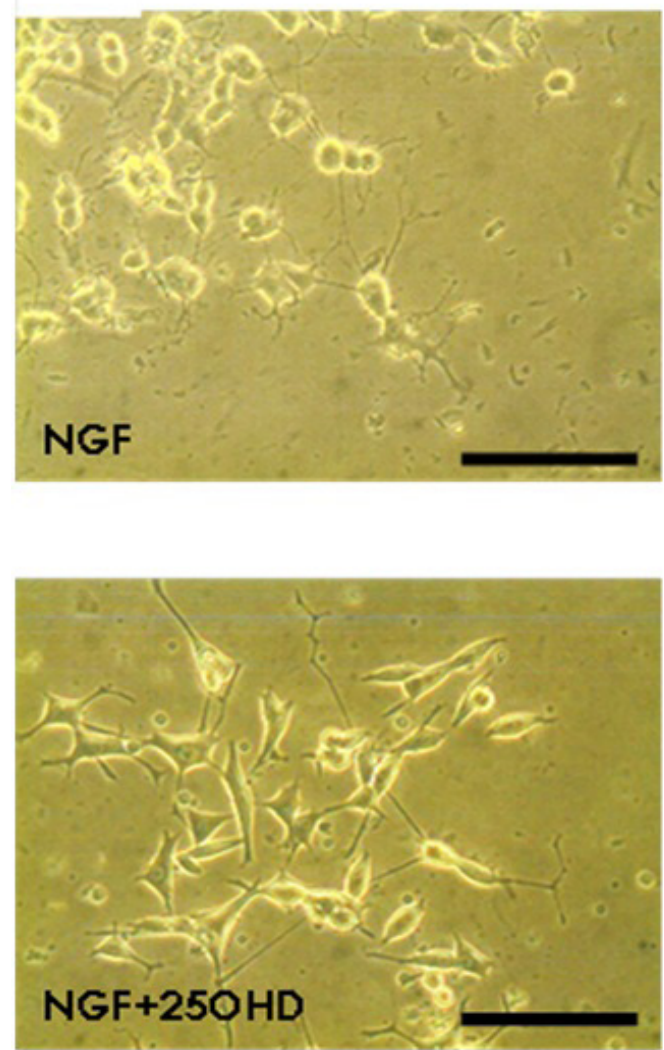

(B)

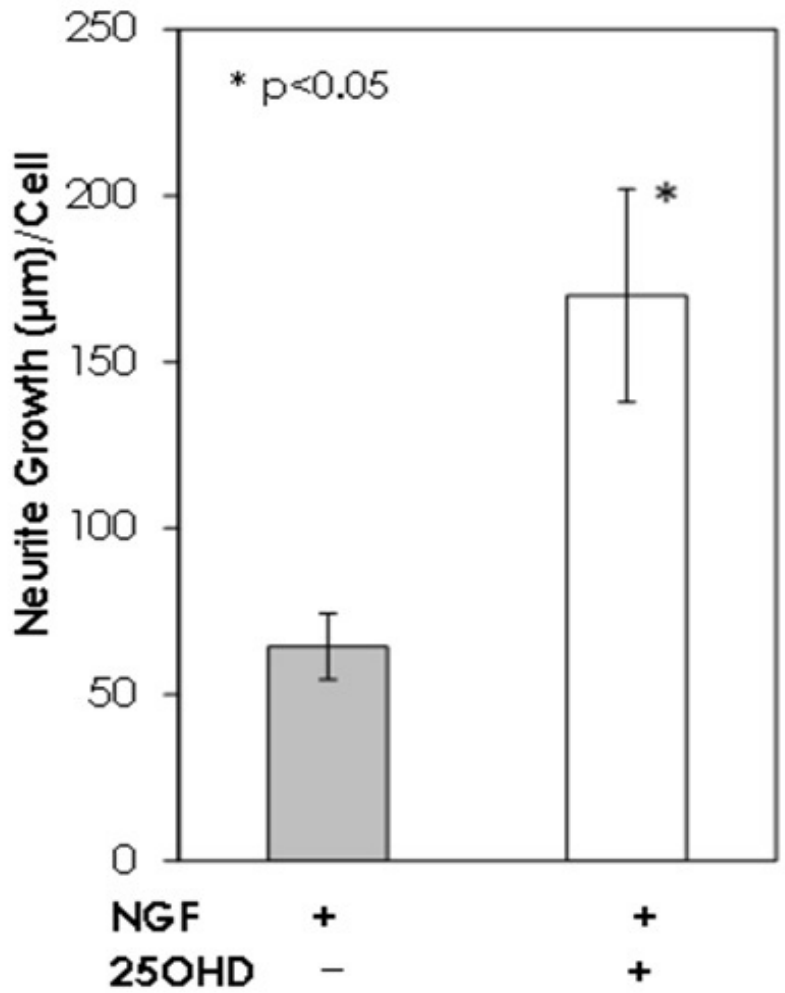

Figure1: Neurite growth in PC12 cells.

(A): Phase-contrast photomicrographs. PC12 cells were treated with $10 \mathrm{ng} / \mathrm{L} \mathrm{NGF}$ in the medium for 4 days with and without $6 \mathrm{nmol} / \mathrm{L}$ of $25 \mathrm{OHD}$.

(B): Neurite outgrowth with and without $6 \mathrm{nmol} / \mathrm{L}$ of $25 \mathrm{OHD}$. Each experiment was repeated three times. Scale bar= $100 \mu \mathrm{m}$.

Data are expressed as mean \pm SE. \# indicates significant differences at $p<0.05$. 
Citation: Mochizuki M, Hasegawa N (2021) 25-Hydroxy Vitamin D Exhibits NGF-like Activity in PC12 Cells. Int J Clin Nutr Diet 7: 159. doi: https:/doi. org/10.15344/2456-8171/2021/159

Page 3 of 4

These results suggest a potential role of $25 \mathrm{OHD}$ in activating protein kinase B (Akt), and in NGF-enhancing and NGF-mimicking neurogenic activity.

Osteocalcin (OC) prevents neuronal apoptosis in the hippocampus [12]. OC crosses the blood-brain barrier, binds to neurons of the brainstem, midbrain, and hippocampus, and enhances the synthesis of monoamine neurotransmitters [12]. OC directly acts to promote cell proliferation and differentiation, and affects the phosphorylation levels of extracellular signal-regulated kinase (ERK) $1 / 2$ in the stimulated PC12 cells [13]. Further study is needed on whether the ERK1/2 signaling pathway is involved in the $25 \mathrm{OHD}$ induced neurogenic activity.

Low vitamin $\mathrm{D}$ has been associated with a risk of developing Alzheimer's disease [14,15]. In our previous study, dementia patients treated with 25OHD for 6 months improved their performance on a cognitive test (MMSE and MoCA-J score) [6]. These results suggest that $25 \mathrm{OHD}$ acts directly to alleviate the impairment of cells in Alzheimer's disease through the blood-brain barrier.
However, no clear evidence on low vitamin D levels as a risk factor for Alzheimer's disease exists, since interventional studies are few [16].

Further study of optimal 25OHD levels for maintaining physical and cognitive functions is needed.

\section{Conclusion}

These findings indicate that $25 \mathrm{OHD}$ might have NGF-like activity in PC12 cells.

\section{Competing Interests}

The authors declare that they have no competing interests.

\section{Author's Contribution}

Ms. Mochizuki was responsible for data acquisition and proofreading of the manuscript and she participated in the data analysis.

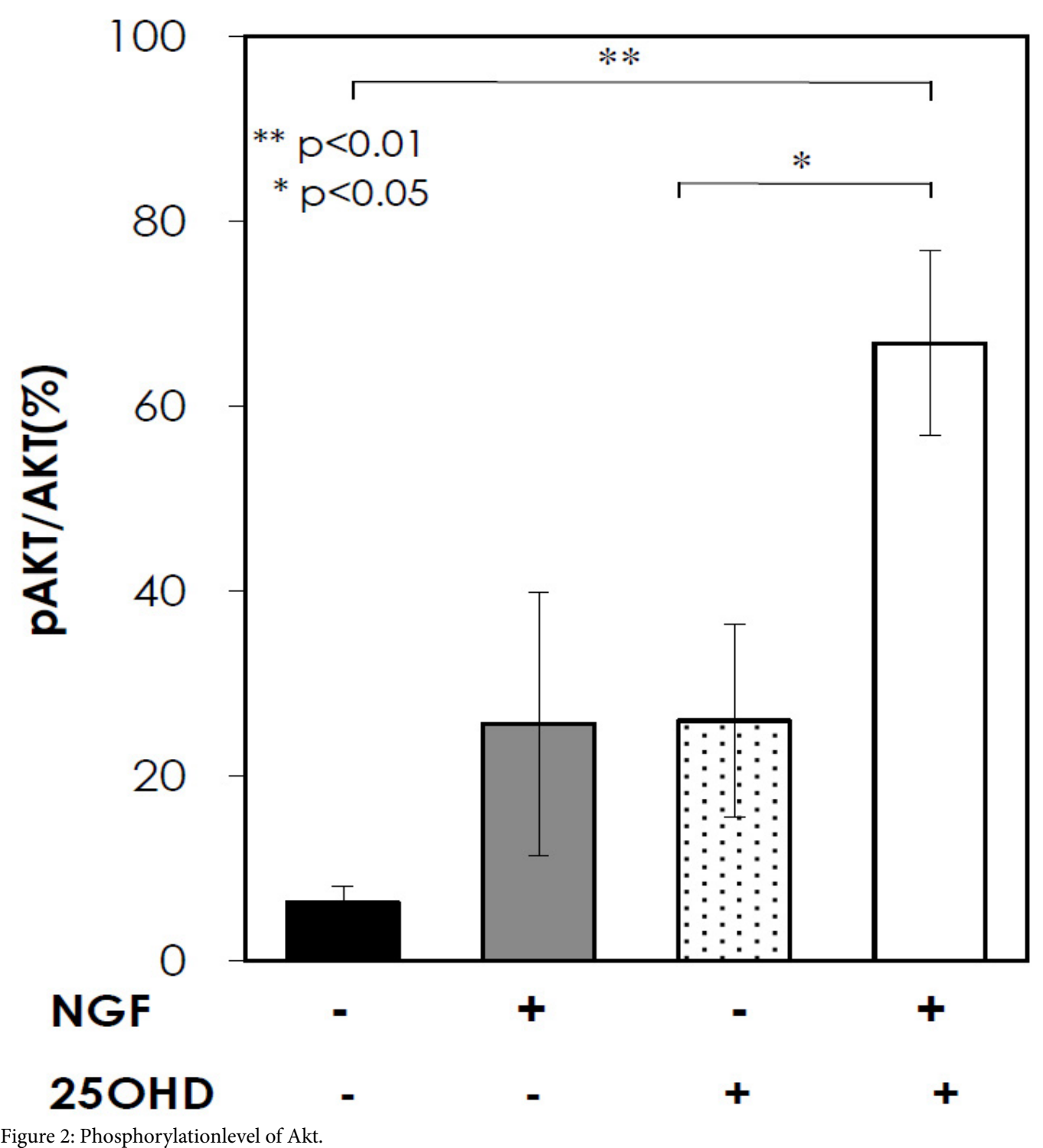


Citation: Mochizuki M, Hasegawa N (2021) 25-Hydroxy Vitamin D Exhibits NGF-like Activity in PC12 Cells. Int J Clin Nutr Diet 7: 159. doi: https://doi. org/10.15344/2456-8171/2021/159

Dr. Hasegawa was responsible for the study conception, design, analysis, interpretation of data, and drafting of the manuscript.

\section{Funding}

This work was supported by KAKENHI (grant number20K02356).

\section{References}

1. Christakos S, Dhawan P, Verstuyf A, Verstuyf A, Verlinden L, et al. (2016) Vitamin D: metabolism, molecular mechanism of action, and pleiotropic effects. Physiol Rev 96: 365-408.

2. DeLuca GC, Kimball SM, Kolasinski J, Ramagopalan SV, Ebers GC, et al. (2013) Review: the role of vitamin D in nervous system health and disease. Neuropathol Appl Neurobiol 39: 458-484.

3. Sarfraz Z (2015) Power of Vitamin D (3rd edition): A Vitamin D Book that Contains the Most Scientific, Useful and Practical Information About Vitamin D - Hormone D. CreateSpace Independent Publishing Platform, USA.

4. Garcion E, Wion-Barbot N, Montero-Menei CN, Berger F, Wion D, et al. (2002) New clues about vitamin D functions in the nervous System. Trends Endocrinol Metab 13: 100-105.

5. Darwish H, Zeinoun P, Ghusn H, Khoury B, Tamim H, et al. (2015) Serum 25-hydroxyvitamin D predicts cognitive performance in adults. Neuropsychiatr Dis Treat 11: 2217-2223.

6. Hasegawa N, Mochizuki M, Yamada T (2019) Vitamin D3 supplementation improved cognitive function in diabetic elderly patients with good glycemic control in Japan: A pilot study. Int J Nurs Clin Pract 6: 311-314.

7. Greene LA, Tischler AS (1976) Establishment of a noradrenergic clona line of rat adrenal pheochromocytoma cells that respond to nerve growth factor. Proc Nat Acad Sci USA 73: 2424-2428.

8. Franke TF, Yang SI, Chan TO, Datta K, Kazlauskas A, et al. (1995) The protein kinase encoded by the Akt proto-oncogene is a target of the PDGFactivated phosphatidylinositol 3-kinase. Cell 81: 727-736.

9. Dudek H, Datta SR, Franke TF, Birnbaum MJ, Yao R, et al. (1997) Regulation of neuronal survival by the serine-threonine protein kinase Akt. Science 275: 661-666.

10. Kobayashi M, Nagata S, Kita Y, Nakatsu N, Ihara S, et al. (1997) Expression of a constitutively active phosphatidylinositol 3-kinase induces process formation in rat PC12 cells. J BiolChem 272: 16089-16092.

11. Hasegawa N, Manabe M, Izumi M, Mochizuki M (2020) Maternal vitamin D in the late first and second trimester is beneficial for healthy development of fetal head circumference. Int J Nurs Clin Pract 7: 330-333.

12. Oury F, Khrimian L, Denny CA, Gardin A, Chamouni A, et al. (2013) Materna and offspring pools of osteocalcin influence brain development and functions. Cell 155: 228-241.

13. Ando E, Higashi S, Mizokami A, Watanabe S, Hirata M, et al. (2021) Osteocalcin promotes proliferation, differentiation, and survival of PC12 cells. Biochem Biopys Res Commun 557: 174-179.

14. Gangwar AK, Rawat A, Tiwari S, Tiwari SC, Narayan J, et al. (2015) Role of vitamin-D in the prevention and treatment of Alzheimer's disease. Indian Physiol Pharmacol 59: 94-99.

15. Annweiler C, Herrmann FR, Fantino B, Brugg B, Beauchet O, et al. (2012) Effectiveness of the combination of memantine plus vitamin $D$ on cognition in patients with Alzheimer disease: A pre-post pilot study. Cogn Behav Neurol 25: 121-127.

16. Bivona G, Sasso BL, Gambino CM, Giglio RV, Scazzone C, et al. (2021) The role of vitamin D as a biomarker in Alzheimer's disease. Brain Sci 11: 334339 